\title{
n-3 Long-chain PUFA reduce allergy-related mediator release by human mast cells in vitro via inhibition of reactive oxygen species
}

\author{
Lieke W. J. van den Elsen ${ }^{1}$, Yvette Nusse ${ }^{1}$, Martin Balvers ${ }^{2}$, Frank A. Redegeld ${ }^{1}$, Edward F. Knol ${ }^{3}$, \\ Johan Garssen ${ }^{1,2}$ and Linette E. M. Willemsen ${ }^{1 *}$ \\ ${ }^{1}$ Division of Pharmacology, Utrecht Institute for Pharmaceutical Sciences, Utrecht University, Universiteitsweg 99,3584 \\ CG Utrecht, The Netherlands \\ ${ }^{2}$ Danone Research, Centre for Specialised Nutrition, Bosrandweg 20, 6704 PH Wageningen, The Netherlands \\ ${ }^{3}$ Department of Dermatology/Allergology, University Medical Center Utrecht, Heidelberglaan 100, 3584 CX Utrecht, \\ The Netherlands
}

(Submitted 16 January 2012 - Final revision received 6 July 2012 - Accepted 7 August 2012 - First published online 1 October 2012)

\section{Abstract}

Increased $n-6$ and reduced $n-3$ long-chain PUFA (LC-PUFA) intake in Western diets may contribute to the increased prevalence of allergic diseases. Key effector cells in allergy are mast cells (MC). The aim of the present study was to investigate the effects of $n$ - $6 v \cdot n$ - 3 LC-PUFA on MC phenotype. Human MC lines (LAD2 and HMC-1) were incubated for $24 \mathrm{~h}$ with either arachidonic acid (AA, $n$ - 6 LC-PUFA) or the $n$ - 3 LCPUFA EPA or DHA. The effects of these three LC-PUFA on degranulation, mediator secretion and reactive oxygen species (ROS) generation were assessed. ROS, mitogen-activated protein kinase (MAPK) or NF- $\mathrm{BB}$ inhibitors were used to unravel signalling pathways involved in cytokine secretion. AA, EPA or DHA did not reduce IgE-mediated degranulation by LAD2 cells. However, AA increased PGD 2 and TNF- $\alpha$ secretion by ionomycin/phorbol 12-myristate 13-acetate-stimulated HMC-1, whereas EPA and DHA more prominently inhibited IL-4 and IL-13 secretion. Suppression of IL-4 and IL-13 release by LC-PUFA correlated with reduced ROS generation. IL- 4 and IL-13 release by activated HMC-1 was abrogated using ROS inhibitors. Inhibition of MAPK signalling, but not NF-kB, downstream of ROS reduced IL-13 secretion by activated HMC-1. Combined incubation of EPA or DHA with MAPK inhibitors further suppressed IL- 13 secretion. In conclusion, the $n$ - 6 LC-PUFA AA enhanced pro-inflammatory mediator production by MC, while the $n$-3 LC-PUFA EPA as well as DHA more effectively suppressed ROS generation and IL- 4 and IL-13 release. This suggests that dietary supplementation with EPA and/or DHA may alter the MC phenotype, contributing to a reduced susceptibility to develop and sustain allergic disease.

Key words: Long-chain PUFA: Mast cell degranulation: Mediator secretion: Reactive oxygen species: Allergy

During the last decades, the prevalence of allergic diseases has dramatically increased ${ }^{(1)}$. Mast cells (MC) are key effector cells in allergy and play a pivotal role in initiating and maintaining allergic reactions and inflammation by the release of numerous inflammatory mediators ${ }^{(2-4)}$. Upon activation, MC immediately release a plethora of preformed mediators such as histamine and proteases that are stored in secretory cytoplasmic granules. Arachidonic acid (AA)-derived eicosanoids and multiple pro-inflammatory chemokines and cytokines, such as allergy-driving IL- 4 and IL-13, are generated de novo ${ }^{(2,5)}$. These mediators are important in the pathogenesis of allergic responses and can increase the susceptibility to develop allergic disease and enhance allergic symptoms ${ }^{(6-10)}$.
PUFA can modulate immune responses. In general, $n$-6 long-chain (LC) PUFA such as AA $(20: 4 n-6)$ are considered to be pro-inflammatory and the $n$-3 LC-PUFA EPA $(20: 5 n-3)$ and DHA (22:6n-3) protect against inflammation ${ }^{(11-14)}$ Decreased dietary intake of $n-3$ LC-PUFA from fatty fish together with the high intake of $n-6$ PUFA from mainly vegetable oils in the Western diet is likely to contribute to the increased incidence of allergic and inflammatory disease in humans over the last decades ${ }^{(14-17)}$. Dietary supplementation with $n$-3 LC-PUFA has been studied to some extent in allergic disease, focusing on prevention. Human pregnancy studies revealed a reduction in infant atopy when women were supplemented with fish oil during pregnancy and lactation ${ }^{(18-23)}$.

Abbreviations: AA, arachidonic acid; COX, cyclo-oxygenase; CRTH2, chemoattractant receptor-homologous molecule expressed on Th2 cells; ERK, extracellular signal-regulated kinase; JNK, c-Jun N-terminal kinase; LC-PUFA, long-chain PUFA; MAPK, mitogen-activated protein kinase; MC, mast cell; MFI, mean fluorescence intensity; PMA, phorbol 12-myristate 13-acetate; ROS, reactive oxygen species. 
n-3 LC-PUFA compete with n-6 LC-PUFA for incorporation into the cell membrane. After release from the membrane, AA can be metabolised by cyclo-oxygenases (COX) and lipoxygenases, resulting in the formation of 2,4-series eicosanoids which support inflammatory responses. By contrast, exchange of AA by $n$-3 LC-PUFA results in the production of 3,5-series eicosanoids which are less potent ${ }^{(11,13,15)}$. Besides modification of the generation of eicosanoids, LC-PUFA may change intracellular signalling pathways and may affect the activation of nuclear transcription factors and consequently gene transcription $^{(11,24)}$. Dietary EPA and DHA have been shown to inhibit the release of pro-inflammatory cytokines (IL-1, IL-6, IL-8 and TNF- $\alpha$ ) by macrophages and mononuclear cells ${ }^{(11,25,26)}$; however, little is known about the effects of LC-PUFA in MC.

In $\mathrm{MC}$, cytokine secretion is under the regulation of intracellular reactive oxygen species (ROS), mitogen-activated protein kinases (MAPK) and NF- $\mathrm{KB}$ signalling pathways ${ }^{(27,28)}$. The pathophysiological importance of ROS such as superoxide generated from MC has not been fully elucidated. At high levels, ROS are involved in the innate immune response while at low levels they are involved in cell signalling ${ }^{(28)}$. It has been described that $n$-3 LC-PUFA may suppress ROS generation by targeting eicosanoids, cytokines and protein kinase $C^{(11,13)}$. These molecules control enzymes involved in ROS formation such as NADPH oxidase ${ }^{(11,28)}$. Wong et al. ${ }^{(29)}$ reported that DHA inhibited NADPH oxidase and ROS generation in macrophages.

Downstream of ROS MAPK extracellular signal-regulated kinase (ERK), p38 and c-Jun N-terminal kinase (JNK) and transcription factors including NF- $\mathrm{kB}$ become activated, resulting in cytokine production ${ }^{(27,30)}$. Precise signalling pathways are still unclear but activation of these routes induces transcriptional activity of cytokine genes in MC.

Although the anti-inflammatory effects of EPA and DHA have been studied in neutrophils and mononuclear cells, the effects on MC function have not been fully addressed. Modulation of MC mediator release, for example by modification of membrane lipid composition, may have an impact on the allergic outcome. In view of the steadily increasing prevalence of allergies and inflammatory diseases, there is a need for (novel) treatment or prevention strategies. Therefore, we studied the effects of AA, EPA and DHA on MC degranulation and cytokine production. In particular, the involvement of ROS, MAPK and NF- $\kappa B$ signalling in cytokine secretion and the modulation of the MC phenotype by LC-PUFA was addressed.

\section{Materials and methods}

\section{Cell culture}

All chemicals and inhibitors were derived from Sigma-Aldrich, unless otherwise stated. Human leukaemic mast cell line HMC-1 was kindly donated by the Mayo Clinic and used with permission ${ }^{(31)}$. These non-adherent cells were cultured in Iscove's modified Dulbecco's medium (Gibco; Invitrogen) supplemented with penicillin $(100 \mathrm{U} / \mathrm{ml})$, streptomycin $(100 \mu \mathrm{g} / \mathrm{ml})$ and $10 \%(\mathrm{v} / \mathrm{v})$ fetal bovine serum (HyClone, Perbio; see Table S1 for fatty acid composition, available online) at $37^{\circ} \mathrm{C}$ with $5 \% \mathrm{CO}_{2}$ in a humidified atmosphere. HMC-1 were passaged once a week.

LAD2 cells were grown in StemPro-34 serum-free complete medium (serum-free medium plus nutrient supplement; Gibco) plus L-glutamine, recombinant human stem cell factor $(100 \mathrm{ng} / \mathrm{ml}$; ProSpec), penicillin $(100 \mathrm{U} / \mathrm{ml})$ and streptomycin $(100 \mu \mathrm{g} / \mathrm{ml})$.

\section{Long-chain PUFA incubation}

For modification of cell lipids, MC were pre-incubated with either AA, EPA or DHA for $24 \mathrm{~h}$. Cells were collected and resuspended at a concentration of $1 \times 10^{6}$ cells $/ \mathrm{ml}$ in fresh medium containing $\mathrm{L}(+)$-ascorbic acid $(75 \mu \mathrm{M}$; Merck) in order to prevent LC-PUFA oxidation. Stock solutions in ethanol of AA, EPA or DHA were further diluted in fetal bovine serum or the StemPro-34 nutrient supplement containing the antioxidant $\alpha$-tocopherol. Then, 5\% fetal bovine serum or $2.5 \%$ nutrient supplement was added to the cells (final concentration of ethanol $\leq 0 \cdot 1 \%(\mathrm{v} / \mathrm{v}))$. The final concentration of $\alpha$-tocopherol was $20 \mu \mathrm{M}$. Control wells also included ethanol $(0 \cdot 1 \%(\mathrm{v} / \mathrm{v}))$. Membrane fatty acid composition in HMC-1 $(0,10,25,50$ and $100 \mu \mathrm{M})$ and LAD2 cells $(0,50$ and $100 \mu \mathrm{M}$ based on HMC-1 results) was assessed by GC as previously described by Bligh \& Dyer ${ }^{(32,33)}$.

\section{IgE-mediated $\beta$-hexosaminidase release assay}

LAD2 cells were incubated for $24 \mathrm{~h}$ with solely AA, EPA or DHA $(0,25,50$ and $100 \mu \mathrm{M}$ chosen from membrane fatty acid analysis) in a ninety-six-well culture plate (Costar; Corning Incorporated) at $1 \times 10^{5}$ cells $/ 100 \mu \mathrm{l}$ per well. Stempro-34 medium without the nutrient supplement but supplemented with $\mathrm{L}(+)$-ascorbic acid was used. The nutrient supplement enriched with $\alpha$-tocopherol or $\alpha$-tocopherol + LC-PUFA was added to determine the degranulation of LC-PUFA-supplemented cells. After $4 \mathrm{~h}$, human purified IgE (Chemicon; Millipore) was added at a concentration of $0.5 \mu \mathrm{g} / \mathrm{ml}$ and incubated for an additional $20 \mathrm{~h}$ at $37^{\circ} \mathrm{C}$, to prime the cells with IgE. The cells were washed two times by Tyrode's buffer (10 mM-HEPES (Acros Organics) buffer, pH 7.2, Tyrode salts (Gibco) 9.5 g/l, $0 \cdot 1 \%$ sodium bicarbonate (Merck), $0 \cdot 1 \%(\mathrm{w} / \mathrm{v})$ bovine serum albumin (fraction V; Roche)). Next, $\alpha$-human IgE-fluorescein isothiocyanate (KPL) was added to a final concentration of $10 \mu \mathrm{g} / \mathrm{ml}$ and incubated for $1 \mathrm{~h}$ at $37^{\circ} \mathrm{C}$ to induce degranulation. Degranulation was determined by the amount of $\beta$-hexosaminidase released in the cell-free supernatant. To determine the total amount of $\beta$-hexosaminidase release present in untreated cells, Triton X-100 (1\%) was used to lyse the cells. Supernatants were diluted 1:1 with $160 \mu \mathrm{M}$-4-methyl umbelliferyl- $N$-acetyl- $\beta$-D-glucosaminide in $0 \cdot 1 \mathrm{M}$-citrate buffer ( $\mathrm{pH} 4.5)$ and incubated for $1 \mathrm{~h}$ at $37^{\circ} \mathrm{C}$. This reaction was terminated by the addition of glycine buffer (15g glycine (MP Biochemicals), $11.7 \mathrm{~g} \mathrm{NaCl} / 1$ (Merck), pH 10.7). Fluorescence was measured within $1 \mathrm{~h}$ at an excitation of $360 \mathrm{~nm}$ and an emission of $460 \mathrm{~nm}$ by a fluorescence measurement system (Millipore, CytoFluor 2350; B\&L Systems). Average fluorescence of unstimulated cells 
(background) was subtracted from all values. Background release did not differ between the groups. The amount of $\beta$-hexosaminidase release was calculated as a percentage of total $\beta$-hexosaminidase in Triton X-100 cell lysates (maximal release).

\section{Mast cell mediator release and cell viability}

After pre-incubation with AA, EPA or DHA, in some experiments, inhibitors were used before MC stimulation. HMC-1 were incubated for $30 \mathrm{~min}$ with $1-10 \mu \mathrm{M}$ of COX inhibitors (indomethacin or NS398) or for $10 \mathrm{~min}$ with a ROS inhibitor (superoxide dismutase; 20 or $100 \mathrm{U} / \mathrm{ml}$ (equivalent to 7 or $35 \mu \mathrm{g} / \mathrm{ml}$ ) or 1,3-dimethyl-2-thiourea; 30, 40, 50 and $60 \mathrm{~mm}$ ), a MAPK inhibitor (ERK inhibitor PD98059; 50 and $100 \mu \mathrm{M}$, p38 inhibitor SB203580; 20 and $50 \mu \mathrm{M}$, JNK inhibitor SP600125; 10 and $20 \mu \mathrm{M}$ ) or an NF-кB inhibitor (Bay117082; 10 and $30 \mu \mathrm{M}$ ). The inhibitors were diluted in medium (final concentration of dimethyl sulphoxide $\leq 0 \cdot 2 \%(\mathrm{v} / \mathrm{v})$, except for PD98059 with $0.5 \%$ dimethyl sulphoxide (v/v)). After pre-incubation with LC-PUFA and/or inhibitors, the cells were stimulated with $1 \mu \mathrm{M}$-ionomycin plus $16 \mathrm{~nm}$-phorbol 12-myristate 13-acetate (PMA) (both diluted in medium, final concentration of dimethyl sulphoxide $0 \cdot 1 \%(\mathrm{v} / \mathrm{v}))$ and incubated at $37^{\circ} \mathrm{C}$. Optimal doses of ionomycin and PMA were chosen after pilot experiments. To assess inflammatory mediator production in the culture supernatants of HMC-1, supernatants were collected $30 \mathrm{~min}\left(\mathrm{PGD}_{2}\right), 4 \mathrm{~h}(\mathrm{TNF}-\alpha$ and IL-8) and $24 \mathrm{~h}$ (IL-4 and IL-13) after stimulation. Secreted cytokine concentrations were determined by ELISA cytoSet kits according to the manufacturer's instruction (BioSource International, Inc.). $\mathrm{PGD}_{2}$ was measured by the Enzyme Immunoassay Prostaglandin $\mathrm{D}_{2}$-MOX kit (Cayman Chemical).

After $24 \mathrm{~h}$ stimulation, cell proliferation/viability reagent WST-1 (Roche) was added to the cells to assess cell viability (mitochondrial activity). Absorbance at $450 \mathrm{~nm}$ was determined using a Bio-Rad Benchmark Microplate Reader (Bio-Rad Laboratories). In separate experiments, cell death (necrosis) was examined by light microscopy with trypan blue exclusion

\section{Intracellular reactive oxygen species production}

Following $24 \mathrm{~h}$ incubation with 0,25 or $100 \mu \mathrm{M}$-AA, EPA or DHA, ROS production by HMC-1 was measured by means of flow cytometry. Cells were washed and resuspended in $200 \mu \mathrm{l}$ fluorescence-activated cell sorter buffer (5\% fetal bovine serum in PBS (BioWhittaker) in a V-shaped ninety-six-well culture plate (Cellstar, Greiner bio-one, TC-plate). Subsequently, the cells were incubated with $5 \mu \mathrm{M}-2^{\prime}, 7^{\prime}$-dichlorofluorescein diacetate for $10 \mathrm{~min}$ at $37^{\circ} \mathrm{C}$ followed by ionomycin and PMA, as described earlier. After $30 \mathrm{~min}$, ROS production was determined as the potency to oxidise $2^{\prime}, 7^{\prime}$-dichlorofluorescein to fluorescent dichlorofluorescein on a FACSCalibur flow cytometer (BD Biosciences), as described previously ${ }^{(27,34)}$. Generation of intracellular ROS was determined by counting of 10000 cells in channel FL1 (excitation $488 \mathrm{~nm}$ and emission $530 \mathrm{~nm}$ ) of the fluorescence-activated cell sorter.

\section{Statistical analysis}

Graphs were made by statistical software GraphPad Prism (GraphPad Prism for Windows, version 4; GraphPad Software, Inc.). Data are presented as means with their standard errors of the different experiments under the same conditions. Differences between the groups were assessed by one-way ANOVA and post hoc Dunnett's test for multiple comparisons. To compare the effects between the different LC-PUFA, one-way ANOVA and post hoc Bonferroni's test for multiple comparisons or paired Student's $t$ test was used. SPSS version 15 software (SPSS, Inc.) was used for these analyses. Pearson's correlation coefficients were calculated by GraphPad Prism. $P<0.05$ was considered as statistically significant.

\section{Results}

\section{Fatty acid composition of human mast cells}

Membrane fatty acid composition of HMC-1 and LAD2 cells was significantly altered after AA, EPA or DHA incubation. These LC-PUFA did incorporate dose-dependently in the cellular membranes of HMC-1 and LAD2 cells (Table 1). Furthermore, incubation with EPA or DHA significantly reduced AA in the cell membrane of HMC-1 and LAD2 cells, while EPA and DHA were substituted significantly by the addition of AA in HMC-1 only due to the lack of EPA and low DHA in LAD2 cells under basal conditions. In addition to exchanges in LC-PUFA membrane composition, AA, EPA or DHA supplementation competed with $18: 1 n-9$ and $16: 0$ for incorporation (data not shown).

\section{Effect of arachidonic acid, EPA or DHA on IgE-stimulated degranulation of LAD2 cells}

$\beta$-Hexosaminidase release was used as a marker for MC degranulation. LAD2 cells were stimulated by sensitisation with IgE followed by cross-linking with $\alpha$-IgE. AA at $100 \mu \mathrm{M}$ increased FceRI-mediated $\beta$-hexosaminidase release of LAD2 cells while EPA and DHA did not affect MC degranulation (AA $100 \mu \mathrm{M}$ : 36.4 (SEM 6.7) v. 49.9 (SEM 5.6) \%, $n$ 3, $P<0.05$; Fig. 1(a)). Degranulation after incubation with AA did not differ significantly from EPA or DHA. The solvent of LC-PUFA (ethanol, $0 \cdot 1 \%(\mathrm{v} / \mathrm{v})$ ) did not affect $\beta$-hexosaminidase release (data not shown).

\section{Modulation of mediator release of HMC-1 by arachidonic acid, EPA or DHA}

To determine the effects of modification of cell membrane fatty acid composition on cytokine production, HMC-1 were used. To study dose-dependency of MC mediator release, HMC-1 were incubated with 0, 1, 10, 25 and $100 \mu \mathrm{M}$-AA, EPA or DHA because this was expected to be more sensitive to changes in cell membrane fatty acid composition than degranulation. As shown in Fig. 1(b), the production of $\mathrm{PGD}_{2}$ increased dramatically in a dose-dependent manner after incubation with AA (13.4 (SEM 6.3) $v$. 71.6 (SEM $24 \cdot 1) \mathrm{ng} / \mathrm{ml}, 25 \mu \mathrm{M}-\mathrm{AA}, n 3, P<0 \cdot 01)$; in contrast, EPA and 
Table 1. Membrane fatty acid composition of HMC-1 and LAD2 cells after $24 \mathrm{~h}$ long-chain PUFA incubation

(Mean values with their standard errors; $n 4$ independent experiments)

\begin{tabular}{|c|c|c|c|c|c|c|c|c|c|c|c|c|c|}
\hline \multirow[b]{3}{*}{ PUFA } & \multirow[b]{3}{*}{ Concentration $(\mu \mathrm{M})$} & \multicolumn{6}{|c|}{ HMC-1 } & \multicolumn{6}{|c|}{ LAD2 } \\
\hline & & \multicolumn{2}{|c|}{ AA (\%) } & \multicolumn{2}{|c|}{ EPA (\%) } & \multicolumn{2}{|c|}{ DHA (\%) } & \multicolumn{2}{|c|}{ AA (\%) } & \multicolumn{2}{|c|}{ EPA (\%) } & \multicolumn{2}{|c|}{ DHA (\%) } \\
\hline & & Mean & SE & Mean & SE & Mean & SE & Mean & SE & Mean & SE & Mean & SE \\
\hline \multirow[t]{5}{*}{ AA } & 0 & 3.4 & 0.4 & 0.3 & 0.1 & $2 \cdot 7$ & 0.3 & $7 \cdot 0$ & 0.4 & 0.0 & 0.0 & $1 \cdot 1$ & 0.1 \\
\hline & 10 & $13 \cdot 6$ & $2 \cdot 2$ & $0.0^{\star \star}$ & 0.0 & 2.0 & 0.2 & & & & & & \\
\hline & 25 & $26 \cdot 4^{\star \star \star}$ & $7 \cdot 0$ & $0.0^{\star \star}$ & 0.0 & $1.4^{*}$ & 0.4 & & & & & & \\
\hline & 50 & $20 \cdot 9^{\star}$ & 1.9 & $0.0^{\star \star}$ & 0.0 & 1.6 & 0.0 & $16 \cdot 4$ & $3 \cdot 1$ & 0.0 & 0.0 & 0.9 & 0.1 \\
\hline & 100 & $33 \cdot 7^{\star \star \star}$ & 0.7 & $0.0^{\star \star}$ & 0.0 & $1 \cdot 2^{\star}$ & 0.1 & $26 \cdot 2^{*}$ & $5 \cdot 0$ & 0.0 & 0.0 & 0.7 & 0.1 \\
\hline \multirow[t]{4}{*}{ EPA } & 10 & $3 \cdot 0$ & 0.3 & $4 \cdot 0$ & 0.3 & 4.4 & 0.9 & & & & & & \\
\hline & 25 & $2 \cdot 7$ & 0.1 & 7.9 & 0.9 & 3.5 & 0.7 & & & & & & \\
\hline & 50 & $2 \cdot 2$ & 0.1 & $11 \cdot 3$ & $2 \cdot 7$ & $2 \cdot 5$ & 0.8 & $6 \cdot 1$ & 0.3 & $5 \cdot 7$ & 1.5 & 1.0 & 0.1 \\
\hline & 100 & $1 \cdot 7^{*}$ & 0.2 & $21 \cdot 5^{\star \star \star}$ & $2 \cdot 0$ & 1.5 & 0.2 & $5 \cdot 6^{*}$ & 0.2 & $13 \cdot 4^{\star}$ & $3 \cdot 7$ & 0.8 & 0.1 \\
\hline \multirow[t]{4}{*}{ DHA } & 10 & 3.0 & 0.3 & 0.8 & 0.3 & $12 \cdot 6$ & 1.0 & & & & & & \\
\hline & 25 & $2 \cdot 6$ & 0.2 & 0.8 & 0.2 & $25 \cdot 0^{\star \star \star}$ & $2 \cdot 4$ & & & & & & \\
\hline & 50 & $2 \cdot 3$ & 0.0 & 0.8 & 0.2 & $34 \cdot 8^{\star \star \star}$ & 4.0 & $6 \cdot 2$ & 0.3 & 0.0 & 0.0 & $16 \cdot 5^{\star}$ & 2.6 \\
\hline & 100 & $1 \cdot 7^{*}$ & 0.2 & 0.7 & 0.1 & $52 \cdot 1^{\star \star \star}$ & $5 \cdot 1$ & $5 \cdot 5^{\star}$ & 0.2 & $0 \cdot 1$ & 0.0 & $28 \cdot 0^{\star \star \star}$ & 3.7 \\
\hline
\end{tabular}

AA, arachidonic acid.

Mean values were significantly different from the control group $(0 \mu \mathrm{M})$ after incubation with AA, EPA or DHA: ${ }^{*} P<0.05$, ${ }^{\star \star} P<0.01,{ }^{\star \star *} P<0.001$ (one-way ANOVA with post hoc Dunnett's multiple comparison test).

DHA inhibited $\mathrm{PGD}_{2}$ production (13.4 (SEM 6.3) v. 3.5 (SEM 1.9) $\mathrm{ng} / \mathrm{ml}, 25 \mu \mathrm{m}$-DHA, $n 3, P<0.05)$. AA ( $25 \mu \mathrm{M})$ was also found to enhance TNF- $\alpha$ secretion by HMC-1 (4.4 (SEm 1.0) v. $10 \cdot 1(\operatorname{sem} 3 \cdot 5) \mathrm{ng} / \mathrm{ml}, n 5, P<0.05)$; no effects were observed for EPA and DHA (Fig. 1(c)). IL-8 secretion was not affected by AA, EPA or DHA (data not shown). However, $24 \mathrm{~h}$ preincubation with AA, EPA or DHA resulted in a decrease in ionomycin/PMA-induced IL-4 and IL-13 release (Fig. 1(d) and (e)). The effects of DHA on IL-13 production were most pronounced since DHA already reduced IL-13 secretion at $25 \mu \mathrm{m}$ (300.1 (SEm 94.5) v. 104.6 (SEm 25.8) pg/ml, $n$ 6, $P<0.01)$. In addition, this was significantly lower than AA-treated cells $(P<0.05)$. AA as well as EPA and DHA reduced IL-13 secretion at a concentration of $100 \mu \mathrm{M}$ (AA 86.8 (sEm 19.7) pg/ml; EPA 38.5 (SEM 13.7) $\mathrm{pg} / \mathrm{ml}$; DHA 44.0 (SEm 14.6) $\mathrm{pg} / \mathrm{ml}, n 6, P<0.01$ ); however, the EPA and DHA treatments resulted in significantly lower IL-13 secretion than AA $(P<0 \cdot 01)$. At the highest concentration used, EPA and DHA were able to reduce IL-4 secretion (119.8 (SEM 50.6) v. $35.7(\operatorname{sem} 10 \cdot 2) ; 32 \cdot 8(\operatorname{sem} 8 \cdot 1) \mathrm{pg} / \mathrm{ml}$ respectively, $n 6$, $P<0 \cdot 05)$. The solvent of LC-PUFA (ethanol, $0 \cdot 1 \%(\mathrm{v} / \mathrm{v}))$ and ionomycin/PMA ( $0 \cdot 1 \%(\mathrm{v} / \mathrm{v})$ dimethyl sulphoxide) did not affect mediator release (data not shown).

Pre-incubation for 30 min with indomethacin (general COX inhibitor; $10 \mu \mathrm{M}$ ) as well as NS398 (COX-2 inhibitor; 1 and $10 \mu \mathrm{M})$ effectively inhibited $\mathrm{COX}$ as $\mathrm{PGD}_{2}$ release was blocked by more than $90 \%$ (data not shown). However, COX inhibitors did not affect TNF- $\alpha$ or IL-13 secretion; hence, these cytokines are not regulated by a COX-dependent mechanism (data not shown).

\section{Arachidonic acid, EPA and DHA do not affect cell viability}

AA, EPA and DHA (0, 1, 10, 25 and $100 \mu \mathrm{M})$ incubation up to $48 \mathrm{~h}$ did not affect cell viability of stimulated HMC- 1 as determined by WST-1 assay. Ionomycin (1 $\mu \mathrm{M})$ and PMA (16nM) stimulation for $24 \mathrm{~h}$ slightly tended to reduce cell viability when compared with non-stimulated HMC-1 (data not shown). EPA tended to induce a slight increase in mitochondrial activity and the WST-1 signal was significantly higher with $100 \mu \mathrm{m}$-AA $(n 6, P<0 \cdot 05)$. Cell viability was also studied by the trypan blue exclusion test. The addition of AA, EPA or DHA did not induce cell death at the concentrations 25 and $100 \mu \mathrm{M}$ (data not shown).

\section{Generation of intracellular reactive oxygen species and modulation by arachidonic acid, EPA or DHA}

ROS are known as second messengers and are related to different inflammatory diseases ${ }^{(27)}$. HMC-1 showed a slight increase in ROS generation upon ionomycin/PMA stimulation (Fig. 2(a)). HMC-1 cells have high basal ROS levels (mean fluorescence intensity (MFI)) and due to limitations in the sensitivity of the method used, additional ROS production upon stimulation was not higher than ROS production in unstimulated cells (MFI 394.8 (SEM 95.3) v. 424.9 (SEM 53.7), NS) (Fig. 2(b)). To study the effect of AA, EPA or DHA on ROS production in ionomycin/PMA-stimulated HMC-1, cells were incubated with 25 and $100 \mu \mathrm{m}$ based on the differences between 25 and $100 \mu \mathrm{M}$ in IL-4 and IL-13 secretion. Intracellular ROS generation is dose-dependently reduced by AA, EPA or DHA in stimulated HMC-1. This effect was most pronounced for DHA, which showed a significant reduction in ROS generation at $25 \mu \mathrm{M}$ (MFI 325.1 (SEM 47.9), $P<0.05$ ) when compared with basal ROS generation after stimulation. This also was significantly lower than the AA-treated cells $(P<0.05)$. At a concentration of $100 \mu \mathrm{M}-\mathrm{AA}, \mathrm{EPA}$ and DHA were all able to reduce ROS generation (AA: MFI 278.2 (SEM 22.6), $P<0.01$; EPA: MFI $267 \cdot 6$ (SEM 47.1), $P<0 \cdot 001$; DHA: MFI $215 \cdot 6$ (SEM 32.1), $P<0.001$ ). ROS generation after stimulation (mean of $n 3$ for each condition, used from Fig. 2(b)) was found to correlate positively with IL-4 and IL-13 secretion (mean of $n 5 / 6$ for 
(a)

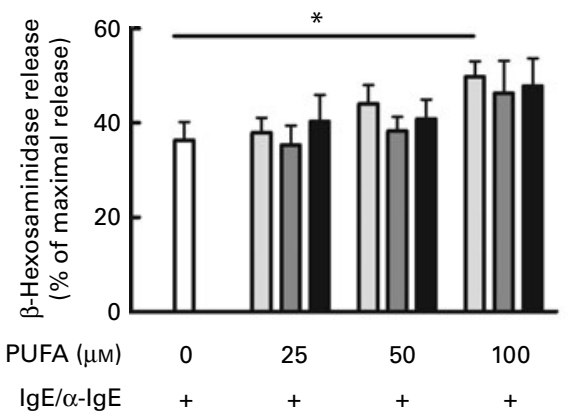

(b)

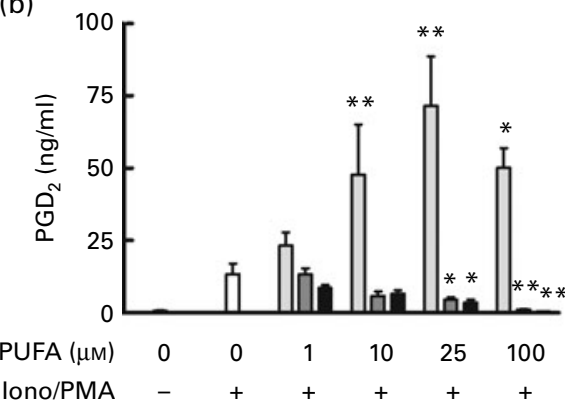

(d)

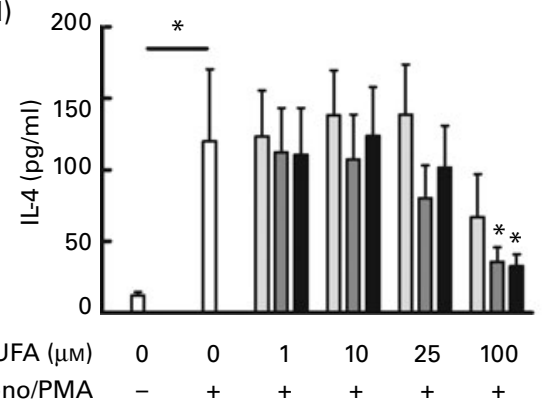

(c)

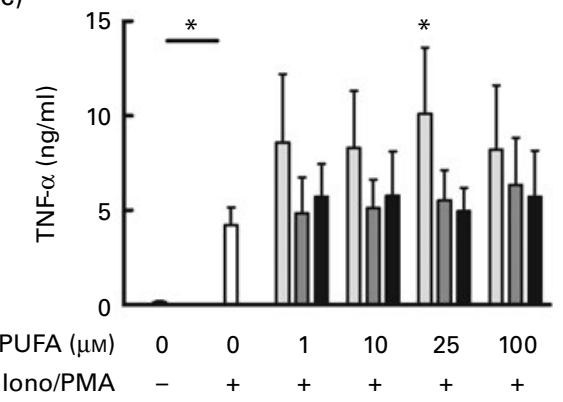

(e)

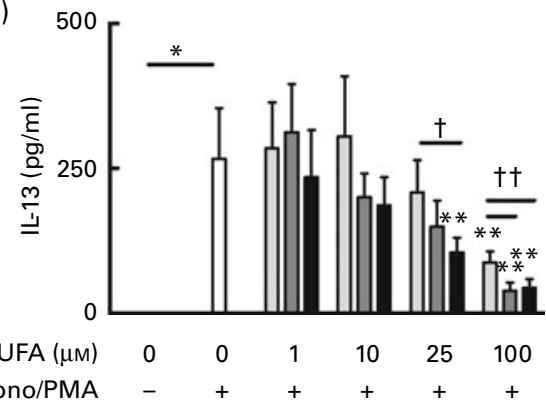

Fig. 1. (a) IgE-mediated degranulation of LAD2 cells $1 \mathrm{~h}$ after $\alpha-\lg E$ stimulation incubated with different concentrations of arachidonic acid (AA, $\square$ ), EPA ( $\square$ ) and DHA ( $\mathbf{n}$. Degranulation was determined by the amount of $\beta$-hexosaminidase release as a percentage of Triton X-100-treated cells. Values are means of three independent experiments, average background release is subtracted, with their standard errors represented by vertical bars. Effect of LC-PUFA on ionomycin/ phorbol 12-myristate 13-acetate (iono/PMA)-induced release of (b) PGD 2 after $30 \mathrm{~min}(n$ 3), (c) TNF- $\alpha$ after $4 \mathrm{~h}(n)$ ), (d) IL-4 after $24 \mathrm{~h}(n 6)$ and (e) IL-13 after $24 \mathrm{~h}(n 6)$ by HMC-1. Values are means, with their standard errors represented by vertical bars. Mean values were significantly different from those of the control group (O+): ${ }^{*} P<0.05,{ }^{* \star} P<0.01$ (one-way ANOVA followed by Dunnett's test for multiple comparisons). Mean values were significantly different between the LC-PUFA: $\dagger P<0.05$, $† \uparrow P<0.01$ (one-way ANOVA followed by Bonferroni's multiple comparison test).

each condition, used from Fig. 1(d) or (e), respectively) in HMC-1 $(P=0 \cdot 006, r 0.897$ and $P=0 \cdot 005, r 0 \cdot 907$, respectively) (Fig. 2(c) and (d)).

\section{Effect of reactive oxygen species inhibition on $I L-4$ and IL-13 secretion}

Since AA, EPA and DHA were able to suppress ROS and IL-4 and IL-13 secretion, it was assessed whether these allergyrelated cytokines were under the regulation of ROS in HMC-1. Pre-incubation with 1,3-dimethyl-2-thiourea at the highest concentrations (40-60 mm) resulted in a decrease in IL-4 secretion of ionomycin plus PMA-stimulated HMC-1 (354.1 ( $($ SEM 122.7) v. 100.4 (SEM 55.2) pg/ml, $60 \mathrm{~mm}, \quad P<0.01$ ) (Fig. 3(a)). IL-13 release was dramatically and dosedependently decreased by 1,3-dimethyl-2-thiourea at all dosages (129.7 (SEM 32.8) v. 7.1 (SEM 2.9) pg/ml, $60 \mathrm{~mm}$,
$P<0.001$ ) (Fig. 3(b)). The addition of superoxide dismutase only resulted in the reduction of the secretion of IL- $4(136 \cdot 0$ (sEM 68.8$) \mathrm{pg} / \mathrm{ml}, 100 \mathrm{U} / \mathrm{ml}(35 \mu \mathrm{g} / \mathrm{ml}), P<0.01)$ but not of IL-13 (Fig. 3(c) and (d)). Incubation with ROS inhibitors did not reduce mitochondrial activity or increase cell death as shown by the WST-1 assay and trypan blue exclusion, respectively (data not shown).

\section{Effects of mitogen-activated protein kinases and NF- $\kappa B$ inhibitors on $I L-13$ release}

ROS have been described to operate upstream in the signalling cascade. MAPK and NF- $\mathrm{KB}$ are known to contribute to cytokine secretion by MC. To determine the involvement of MAPK and NF- $\mathrm{BB}$ signalling in the secretion of IL-13 and the possible effects of LC-PUFA on these pathways, we examined the effects of the ERK inhibitor PD98059, the p38 inhibitor 
(a)

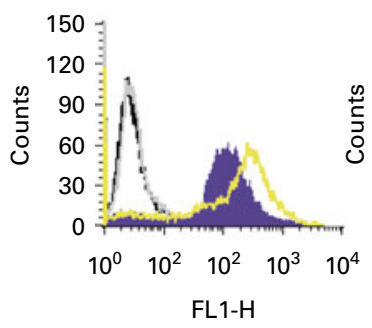

(c)

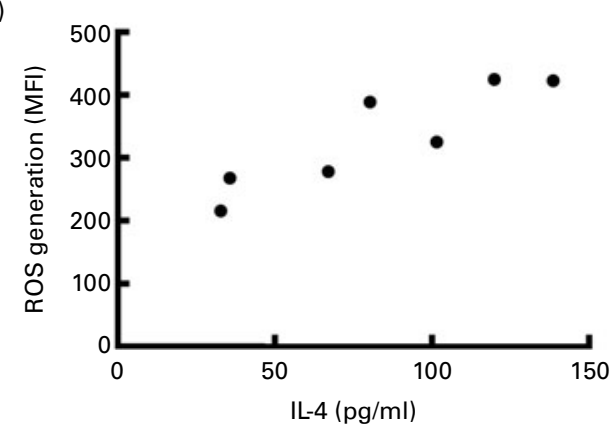

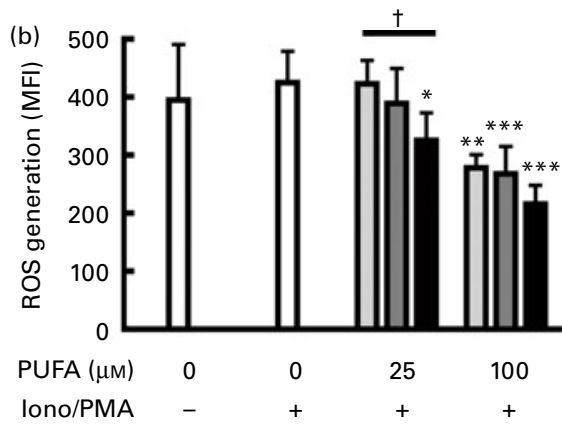

(d)

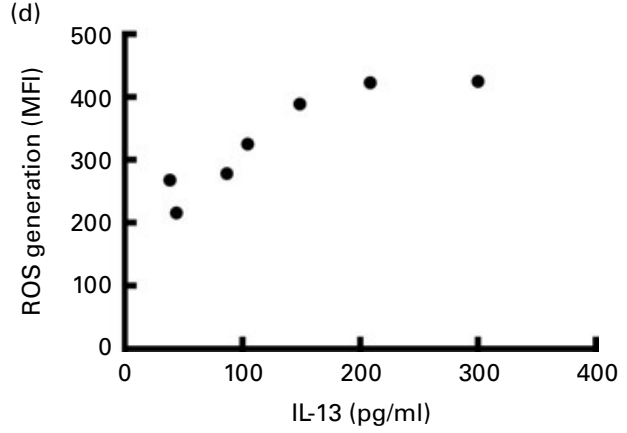

Fig. 2. (a) Generation of reactive oxygen species (ROS) in HMC-1 increased by stimulation with ionomycin/phorbol 12-myristate 13-acetate (lono/PMA) as compared with unstimulated HMC-1 cells (left). Long-chain PUFA (LC-PUFA) reduced ROS generation in stimulated HMC-1 in a dose-dependent manner (shift to left) as shown in this example for DHA (25 and $100 \mu \mathrm{M})$ (right). — - Unlabelled - iono/PMA; — , unlabelled + iono/PMA; $\square, 0$ - iono/PMA; — , $0+$ iono/PMA; ,$- 25 \mu \mathrm{M}+$ iono/PMA; -, $100 \mu \mathrm{M}+$ iono/PMA. (b) ROS generation $(n)$ ) by iono/PMA-stimulated HMC-1 after LC-PUFA incubation in mean fluorescence intensity (MFI). Values are means, with standard errors represented by vertical bars. $\square$, AA; $\square$, EPA; $\mathbf{\square}$, DHA. ROS (mean of $n 3$ per data point) were found to correlate positively with (c) IL-4 (mean of $n 6$; $P=0.006$, Pearson's correlation coefficient (r) 0.897) and (d) IL-13 (mean of $n$ 6; $P=0.005, r 0.907$ ) secretion in HMC-1. Mean values were significantly different from those of the control group $(0+)$ : ${ }^{*} P<0.05,{ }^{* *} P<0.01$, ${ }^{\star * *} P<0.001$ (one-way ANOVA followed by Dunnett's test for multiple comparisons). Mean values were significantly different between the LC-PUFA: $\uparrow P<0.05$ (one-way ANOVA followed by Bonferroni's multiple comparison test).

SB203580, the JNK inhibitor SP600125 and the NF-кB inhibitor Bay117082 on IL-13 release by HMC-1 in the absence or presence of pre-incubation with $25 \mu \mathrm{m}$-LC-PUFA since at this concentration, the differences between AA $v$. EPA or DHA on the suppression of IL-13 secretion were most pronounced. The solvents did not have an effect on mediator release (data not shown).

At the concentration of $25 \mu \mathrm{M}$, DHA reduced ionomycin/ PMA-induced IL-13 secretion by HMC-1 by $30 \%(316 \cdot 1$ (SEM 60.2) v. 218.6 (SEM 44.8) pg/ml, $P<0 \cdot 05$; Fig. 4). SB203580 $(20 \mu \mathrm{M}), \operatorname{SP} 600125(10 \mu \mathrm{M})$ and PD98059 $(50 \mu \mathrm{M})$ inhibited IL-13 secretion by more than $50 \%$ (139.6 (SEM 33.6), 114.2 (SEM 61.9) and $147 \cdot 3$ (SEM 38.9) pg/ml, respectively). At higher concentrations, the p38 or JNK inhibitor was even more effective in the suppression of IL-13 secretion (SB203580, $50 \mu \mathrm{M}$ : 60.9 (SEM 15.1) pg/ml; SP600125, $20 \mu \mathrm{M}$ : $27 \cdot 0$ (SEM 23.9) $\mathrm{pg} / \mathrm{ml}$ ) but not the ERK inhibitor (PD98059, $100 \mu \mathrm{M}: 200 \cdot 0 \quad(\mathrm{sem} 56 \cdot 3) \mathrm{pg} / \mathrm{ml}$ ). In contrast, Bay117082 $(10 \mu \mathrm{M})$ did not inhibit IL-13 release, whereas at the concentration of $30 \mu \mathrm{M}$, it strongly reduced cell viability. Simultaneous treatment of the MAPK or NF-кB inhibitor with DHA induced a further inhibition in IL-13 release using suboptimal SB203580 and SP600125 incubation (41.7 (SEM 8.3) and 34.2 (sEm 12.7 ) $\mathrm{pg} / \mathrm{ml}, P<0.05$ and $P=0.07$, respectively). At the concentration of $25 \mu \mathrm{m}$, EPA was able to further reduce IL-13 release in combination with SB203580 when compared with the inhibitor alone $(67.7$ (SEM 10.8$) \mathrm{pg} / \mathrm{ml}, P<0.05$ ), while AA did not add to the effect of the MAPK or NF- $\mathrm{kB}$ inhibitor used (data not shown). The MAPK and NF-кB inhibitors did not enhance cell death in HMC-1. Trypan blue exclusion showed that at the end of the experiment, cell viability was $>80 \%$ (data not shown).

\section{Discussion}

Upon activation, MC initiate and maintain allergic inflammation due to the release of various inflammatory mediators. MC-derived mediators such as $\mathrm{PGD}_{2}, \mathrm{TNF}-\alpha$, IL- 4 and IL-13 increase the susceptibility to develop allergic disease and enhance allergic symptoms ${ }^{(6-10)}$. The present study shows the differential effects of the $n-6$ LC-PUFA AA $v$. the $n-3$ LC-PUFA EPA or DHA on mast cell phenotype.

IgE-mediated MC degranulation was enhanced upon $24 \mathrm{~h}$ pre-incubation with AA. The LAD2 cell line is the only human analogue that can degranulate in an IgE-dependent manner. Teshima et al. ${ }^{(35)}$ found AA and other n-6 PUFA to increase degranulation in rat basophilic leukaemia (RBL-2H3) cells, while $n-3$ PUFA including EPA had no effect. Nakano et $a l .{ }^{(34)}$ reported that AA significantly increased $\beta$-hexosaminidase release upon IgE-antigen stimulation and EPA showed the same tendency. An increase in the content of PUFA in membrane phospholipids is accompanied by an increase in membrane fluidity (decrease in microviscosity) ${ }^{(36,37)}$. MC degranulation may occur more easily when the membrane is more fluid, which may explain the significant increase in degranulation after AA incubation. 
(a)
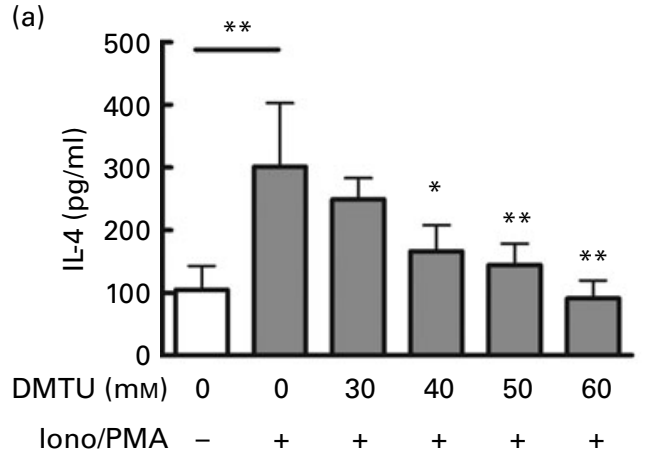

(b)

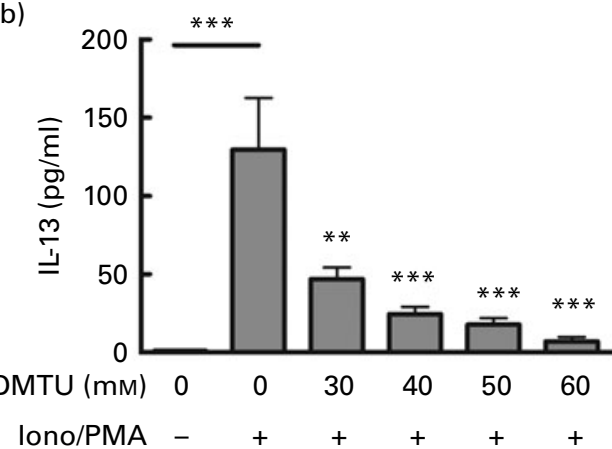

(c)

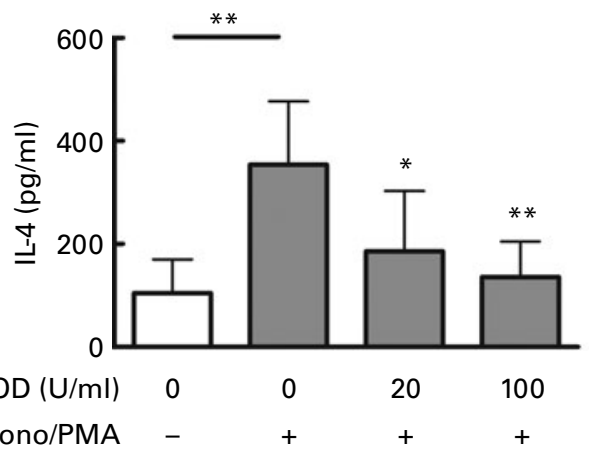

(d)

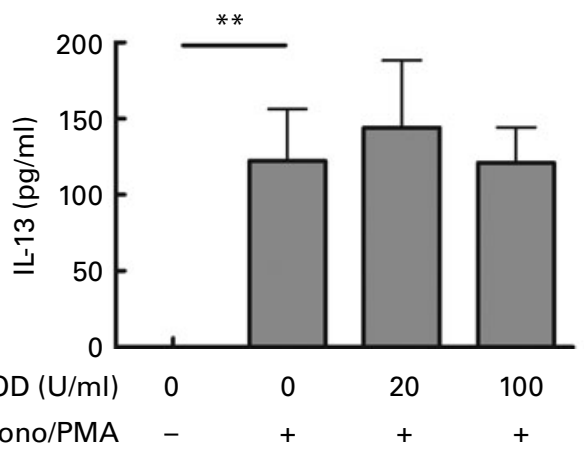

Fig. 3. Effect of incubation with the general reactive oxygen species (ROS) inhibitor 1,3-dimethyl-2-thiourea (DMTU) on (a) IL-4 and (b) IL-13 secretion Contribution of superoxide on (c) IL-4 and (d) IL-13 release was assessed by determining the effect of the specific ROS inhibitor superoxide dismutase (SOD). Values are means, with standard errors represented by vertical bars. Mean values were significantly different from those of the control group $(0+)$ : ${ }^{*} P<0.05$, ${ }^{\star \star} P<0.01,{ }^{* \star} P<0.001$ (one-way ANOVA followed by Dunnett's test for multiple comparisons). Iono/PMA, ionomycin/phorbol 12-myristate 13-acetate.

The same trend was shown for EPA and DHA. In addition to membrane fluidity, LC-PUFA may affect events in signal transduction and MC mediator release. IgE-mediated MC activation involves recruitment of tyrosine kinase, linker for activation of $\mathrm{T}$ cells and Syk, as well as Ca mobilisation ${ }^{(38)}$. Nakano et $a l^{\left({ }^{(3)}\right.}$ have shown that supplementation of RBL-2H3 cells with AA or EPA augmented the activation of linker for activation of $\mathrm{T}$ cells and Syk when compared with control cells. In addition, AA-supplemented cells had increased intracellular Ca concentration ${ }^{(34,35)}$.

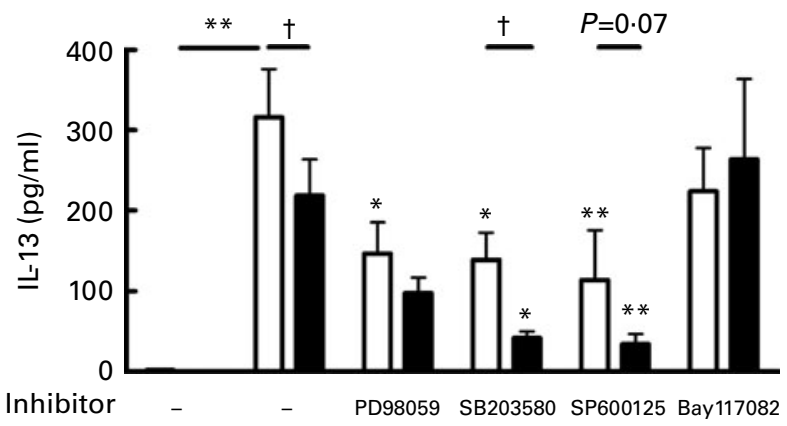
Iono/PMA

Fig. 4. Effect of the extracellular signal-regulated kinase inhibitor PD98059 $(50 \mu \mathrm{M})$, the p38 inhibitor SB203580 $(20 \mu \mathrm{M})$, the c-Jun $\mathrm{N}$-terminal kinase inhibitor SP600125 $(10 \mu \mathrm{M})$ and the NF-кB inhibitor Bay117082 $(10 \mu \mathrm{M})$ in the presence or absence of DHA on ionomycin/phorbol 12-myristate 13-acetate (Iono/PMA)-induced IL-13 release by HMC-1. Values are means, with standard errors represented by vertical bars. Mean values were significantly different from those of the control group $(0+)$ : ${ }^{*} P<0.05$, ${ }^{\star *} P<0.01$ (one-way ANOVA followed by Dunnett's test for multiple comparisons). Mean values were significantly different: $\uparrow P<0.05$ (paired Student's $t$ test). $\square, 0 ; \mathbf{\square}, \mathrm{DHA}$.
Besides LAD2 cells, HMC-1 is often used as a human MC line to circumvent costly isolation procedures for human tissue MC. They lack a functional IgE receptor but can be cultured in large quantities and produce sufficient amounts of mediators for analysis. To simulate IgE receptor signalling, the cells are stimulated by ionomycin (Ca ionophore) and PMA (activating protein kinase $\mathrm{C}$ ). FceRI signalling in $\mathrm{MC}$ also leads to the simultaneous activation of $\mathrm{Ca}$ and protein kinase $\mathrm{C}$, by inositol triphosphate and diacylglycerol, respectively ${ }^{(39)}$. Hence, similar downstream signalling pathways are activated and these pathways act synergistically to provide exocytosis.

Supplementation of LC-PUFA to HMC-1 or LAD2 cells readily resulted in effective AA, EPA or DHA membrane incorporation in a dose-dependent manner. LC-PUFA incorporation seems to be slightly less efficient in LAD2 cells when compared with HMC-1, which may be the result of serum-free culturing of these cells. In both MC lines, EPA and DHA incorporate at the cost of AA and vice versa, which results in changes in membrane $n-6: n-3$ LC-PUFA and EPA:DHA ratios due to alterations in membrane composition. In addition, $18: 1 n-9$, followed by 18:0 and 16:0, were exchanged for the supplemented AA, EPA or DHA (data not shown), enabling efficient incorporation of high amounts of LC-PUFA having implications for the biological function of MC.

The differential effects of $n-3 v \cdot n-6$ LC-PUFA on cytokine secretion by HMC-1 were demonstrated in the present study. The $n-6$ LC-PUFA AA increased TNF- $\alpha$ and $\mathrm{PGD}_{2}$ secretion by HMC-1, while the $n-3$ LC-PUFA EPA and DHA dose-dependently reduced $\mathrm{PGD}_{2}$ release and were most effective in suppressing allergy-driving IL-4 and IL-13 secretion. 
These MC mediators are important in the initiation and persistence of the allergic response ${ }^{(6-10)}$. Besides their role in allergic disease, MC and their products can regulate the adaptive (acquired) immune response via the effects on the maturation, function and migration of $\mathrm{B}$ cells, $\mathrm{T}$ cells and dendritic cells ${ }^{(3,40)}$.

The pro-inflammatory effect of AA is clearly demonstrated by the dramatic induction of $\mathrm{PGD}_{2}$ release. In contrast to $\mathrm{AA}, \mathrm{EPA}$ and DHA reduced $\mathrm{PGD}_{2}$ secretion by activated HMC-1. EPA has been shown to reduce IgE-mediated $\mathrm{PGD}_{2}$ generation by cultured human $\mathrm{MC}$ as well ${ }^{(41)}$. $\mathrm{PGD}_{2}$ is the main prostanoid secreted by activated $\mathrm{MC}$ and associated with allergic diseases. It can decrease IL-12 secretion by dendritic cells and promote Th2 polarisation ${ }^{(42,43)}$. Furthermore, $\mathrm{PGD}_{2}$ is important in the MC-dependent activation of Th2 lymphocytes, eosinophils and basophils via chemoattractant receptor-homologous molecule expressed on Th2 cells $(\mathrm{CRTH} 2)^{(7)}$. Recently, CRTH2 antagonists have shown to be promising in the treatment of asthma and related disorders. A randomised, double-blind comparison of a CRTH2 antagonist and placebo in a population with moderate persistent asthma showed beneficial effects of the CRTH2 antagonist, including an improvement in lung function and asthma symptoms $^{(44)}$. These results provide evidence for an important role for $\mathrm{PGD}_{2}$ in asthma and other allergic disorders, which implicate a beneficial effect of EPA and DHA by reducing $\mathrm{PGD}_{2}$ generation in these patients.

Nakano et al. ${ }^{(34)}$ reported that AA dose-dependently augmented TNF- $\alpha$ release using RBL-2H3 cells, similar to what was shown in these experiments in human MC. MC-derived TNF- $\alpha$ has recently been incriminated to worsen allergic symptoms via the induction of adhesion molecules, enabling influx of inflammatory cells resulting in, for example, airway inflammation and the development of airway hyperresponsiveness ${ }^{(6)}$. However, studies using antiTNF- $\alpha$ treatment have not been consistent, showing marked heterogeneity in responses ${ }^{(45,46)}$. This makes the involvement of TNF- $\alpha$-dependent pathways in LC-PUFA effects less likely.

The present study showed that EPA and DHA, in particular DHA, most effectively inhibit IL-4 and IL-13 secretion from human MC. This has not been reported previously. AA was also able to reduce IL-13 secretion but less effectively than EPA or DHA, while enhancing TNF- $\alpha$ and $\mathrm{PGD}_{2}$ secretion. IL-13 is produced by Th2 cells, MC, eosinophils and basophils, and is critical in the induction and persistence of allergic disease. In allergic asthma, IL-13 is required for the induction of clinical symptoms ${ }^{(8-10)}$. Furthermore, cytokines including IL-4 and IL-13 affect B-cell development and induce IgE isotype switching ${ }^{(47)}$. Recent studies reporting about fish oil supplementation during pregnancy have shown inhibition of IL-13 release by neonatal mononuclear cells in response to allergens as well as reduced levels of IL-13 in cord blood plasma ${ }^{(19,48)}$.

LC-PUFA are known to affect signal transduction cascades, leading to the transcription and production of cytokines. A variety of tissues and cells, including MC, produce ROS such as superoxide and $\mathrm{H}_{2} \mathrm{O}_{2}$ upon stimulation which are upstream regulators of signal transduction pathways ${ }^{(27,30)}$. Although the effect of ionomycin/PMA stimulation on ROS production by
HMC-1 was small in the present experiments, the reduction in ROS generation after LC-PUFA supplementation appeared to be specific for activated MC. Furthermore, within these experiments, IL- 4 and IL-13 secretion by HMC- 1 after stimulation was found to correlate positively with the amount of ROS. This is in agreement with a study in bone marrowderived MC in which IL-4 and IL-13 secretion after IgEmediated activation was associated with increased ROS generation $^{(49)}$. Unfortunately, no sensitive method for measuring intracellular ROS generation upon cell activation is currently available, while only minor changes in ROS upon activation are required to activate intracellular signalling cascades $^{(28)}$. Similar to the present in vitro results, fish oil has been shown to decrease ROS production in several animal studies and in healthy human volunteers ${ }^{(50-54)}$. By contrast, other animal studies have reported contradictory results for ROS production in macrophages after fish oil supplementation $^{(55,56)}$. Studies assessing the impact of LC-PUFA on ROS production in MC are rare. Nakano et al. ${ }^{(34)}$ found that AA and EPA enhance ROS production in stimulated RBL-2H3 cells. The canine mastocytoma cell line C2 was incubated with 18:2n-6 (linoleic acid), AA, 18:3n-3 ( $\alpha$-linolenic acid) and EPA, which all increased ROS production. However, this was possibly due to lipid peroxidation since antioxidant supplementation resulted in a lower increase in ROS production $^{(57)}$. LC-PUFA, in general, are oxidised easily because of their high degree of unsaturation, and thereby form oxygen radicals in many cell types ${ }^{(27,58)}$. In the present experiments in HMC-1, the antioxidants $\mathrm{L}(+)$-ascorbic acid and $\alpha$-tocopherol were used, which act as free radical scavengers and protect LC-PUFA from harmful lipid peroxidation and neutralise the free radicals formed. This may explain some of the discrepancies observed in the effects of LC-PUFA on ROS generation in in vitro studies. As suggested by others, the number of double bonds present may be important in the anti-inflammatory effects generated by LC-PUFA. It may explain the most potent inhibition of ROS generation by the fatty acid with the highest degree of unsaturation, namely DHA. This possibly results in the inhibition of IL- 4 and IL-13 secretion by $\mathrm{AA}<\mathrm{EPA}<\mathrm{DHA}^{(59)}$. The present results imply that EPA and DHA act via similar mechanisms in the suppression of IL-4 and IL-13 secretion from MC, DHA just being slightly more effective than EPA. Probably the antiallergic effects of AA are overruled since AA also enhances pro-inflammatory $\mathrm{PGD}_{2}$ and $\mathrm{TNF}-\alpha$ secretion. Indeed, it has been shown that high maternal intake of margarine and vegetable oils rich in $n$ - 6 PUFA during the last 4 weeks of pregnancy is associated with enhanced occurrence of atopic eczema in offspring ${ }^{(60)}$; by contrast, fish oil supplementation during pregnancy and lactation reduces the susceptibility of developing allergic disease in the neonates ${ }^{(18-23)}$

Use of ROS inhibitors confirmed the involvement of ROS in the IL- 4 and IL-13 secretion pathway in MC. ROS consist of a number of different mediators and although both IL- 4 and IL-13 secretion could be blocked using the general ROS inhibitor 1,3-dimethyl-2-thiourea, use of superoxide dismutase showed that IL- 4 but not IL-13 secretion is under the regulation of superoxide. LC-PUFA may be less able to affect this 
superoxide cascade in relation to other ROS mediators since IL-13 was suppressed more effectively by $n$-3 LC-PUFA than IL-4. ROS generation by MC can contribute to the secretion of inflammatory cytokines via NF- $\mathrm{BB}$ and/or MAP kinase signalling ${ }^{(61)}$. Previous studies have shown that IL-13 secretion by RBL-2H3 cells is regulated by JNK and p38 ${ }^{(62)}$. However, as revealed using inhibitors of these pathways, the MAPK ERK, p38 and JNK were all involved in IL-13 secretion by activated HMC-1, while the NF-кB inhibitor Bay117082 did not reduce IL-13 release. This suggests ROS generation to be upstream of the MAPK signalling cascade.

Recently, a study with anti-IL-4/IL-13 demonstrated an improvement in asthma endpoints in patients with severe, uncontrolled asthma ${ }^{(63)}$, suggesting a possible role for dietary supplementation with the $n$ - 3 LC-PUFA EPA and DHA in allergic disease. However, even though some studies have reported modest improvement of atopic dermatitis, there is no convincing evidence yet for dietary n-3 LC-PUFA supplementation alone for the treatment of those with established atopic disease ${ }^{(64,65)}$. Thus, although AA, EPA and DHA suppress allergy-related mediator release by $\mathrm{MC}$, the effects are moderate and may not be strong enough for treatment purposes. However, when MC were treated with suboptimal doses of DHA and MAPK inhibitors, the suppression of IL-13 secretion by the p38 inhibitor SB203580 (20 $\mu \mathrm{M})$ and the JNK inhibitor SP600125 $(10 \mu \mathrm{M})$, but not the ERK inhibitor PD98059 nor the NF- $\mathrm{B}$ inhibitor Bay117082, was further supported by DHA. The addition of DHA to p38 and JNK inhibitors was as effective as the higher inhibitor doses tested (50 and $20 \mu \mathrm{M}$, respectively). In addition to DHA, EPA was able to support SB203580 in the suppression of IL-13 secretion, while AA did not enhance the efficacy of any of the inhibitors. Hence, the combination of $n$ - 3 LC-PUFA with other drugs seems to be promising in reducing allergic type mediator release of MC. EPA and more prominently DHA, but not AA, added to the inhibitory effect of MAPK inhibitors on IL-13 secretion. Dietary $n$-3 LC-PUFA may therefore be able to optimise the efficacy and/or safety of novel strategies to treat allergies using drugs aiming to suppress IL-4, IL-13 and/or $\mathrm{PGD}_{2}$.

In conclusion, the $n-6$ LC-PUFA AA promotes the allergic cascade by enhancing degranulation and TNF- $\alpha$ and $\mathrm{PGD}_{2}$ secretion by activated MC. In contrast, the $n-3$ LC-PUFA EPA and DHA suppress PGD 2 , IL-13 and IL- 4 secretion as well as ROS generation most effectively. Hence, LC-PUFA differentially modulate the MC phenotype. MC are involved in the initiation and perpetuation of allergic disease, and the suppression of allergy-related mediators by dietary $n-3$ LC-PUFA may contribute to reduced susceptibility to develop or sustain allergic disease.

\section{Supplementary material}

To view supplementary material for this article, please visit http://dx.doi.org/10.1017/S0007114512003959

\section{Acknowledgements}

This study was financially supported by a grant from the Nutricia Research Foundation. The authors' responsibilities were as follows: L. E. M. W. and L. W. J. v. d. E. designed the study with input from F. A. R., E. F. K. and J. G.; L. W. J. v. d. E. and $\mathrm{Y}$. N. performed the experiments under the supervision of L. E. M. W.; F. A. R. provided LAD2 cells; M. B. analysed the mast cell membrane composition; L. W. J. v. d. E. and L. E. M. W. analysed the data; L. W. J. v. d. E. drafted the manuscript and all authors contributed to and approved the final version of the manuscript. None of the authors has any financial or personal conflict of interest to report.

\section{References}

1. Bach JF (2002) The effect of infections on susceptibility to autoimmune and allergic diseases. $N$ Engl J Med 347, 911-920.

2. Metz M \& Maurer M (2007) Mast cells - key effector cells in immune responses. Trends Immunol 28, 234-241.

3. Galli SJ, Nakae S \& Tsai M (2005) Mast cells in the development of adaptive immune responses. Nat Immunol $\mathbf{6}$, 135-142.

4. Metcalfe DD, Baram D \& Mekori YA (1997) Mast cells. Physiol Rev 77, 1033-1079.

5. Stone KD, Prussin C \& Metcalfe DD (2010) IgE, mast cells, basophils, and eosinophils. J Allergy Clin Immunol 125, S73-S80.

6. Chai OH, Han EH, Lee HK, et al. (2011) Mast cells play a key role in Th2 cytokine-dependent asthma model through production of adhesion molecules by liberation of TNF-alpha. Exp Mol Med 43, 35-43.

7. Pettipher R, Hansel TT \& Armer R (2007) Antagonism of the prostaglandin $\mathrm{D}_{2}$ receptors DP1 and CRTH2 as an approach to treat allergic diseases. Nat Rev Drug Discov 6, 313-325.

8. Wang M, Takeda K, Shiraishi Y, et al. (2010) Peanutinduced intestinal allergy is mediated through a mast cell-IgE-FcepsilonRI-IL-13 pathway. J Allergy Clin Immunol 126, 306-316, e301-e312.

9. Taube C, Wei X, Swasey CH, et al. (2004) Mast cells, Fc epsilon RI, and IL-13 are required for development of airway hyperresponsiveness after aerosolized allergen exposure in the absence of adjuvant. I Immunol 172, 6398-6406.

10. Brandt EB, Munitz A, Orekov T, et al. (2009) Targeting IL-4/ IL-13 signaling to alleviate oral allergen-induced diarrhea. J Allergy Clin Immunol 123, 53-58.

11. Calder PC (1997) n-3 Polyunsaturated fatty acids and immune cell function. Adv Enzyme Regul 37, 197-237.

12. Calder PC (2006) Polyunsaturated fatty acids and inflammation. Prostaglandins Leukot Essent Fatty Acids $\mathbf{7 5}$, 197-202.

13. Stulnig TM (2003) Immunomodulation by polyunsaturated fatty acids: mechanisms and effects. Int Arch Allergy Immunol 132, 310-321.

14. Prescott SL \& Calder PC (2004) n-3 Polyunsaturated fatty acids and allergic disease. Curr Opin Clin Nutr Metab Care 7, 123-129.

15. Simopoulos AP (2002) Omega-3 fatty acids in inflammation and autoimmune diseases. J Am Coll Nutr 21, 495-505.

16. Calder PC \& Grimble RF (2002) Polyunsaturated fatty acids, inflammation and immunity. Eur J Clin Nutr 56, Suppl. 3, S14-S19.

17. Black PN \& Sharpe S (1997) Dietary fat and asthma: is there a connection? Eur Respir J 10, 6-12.

18. Lauritzen L, Kjaer TM, Fruekilde MB, et al. (2005) Fish oil supplementation of lactating mothers affects cytokine production in 2 1/2-year-old children. Lipids 40, 669-676. 
19. Dunstan JA, Mori TA, Barden A, et al. (2003) Fish oil supplementation in pregnancy modifies neonatal allergenspecific immune responses and clinical outcomes in infants at high risk of atopy: a randomized, controlled trial. J Allergy Clin Immunol 112, 1178-1184.

20. Furuhjelm C, Warstedt K, Larsson J, et al. (2009) Fish oil supplementation in pregnancy and lactation may decrease the risk of infant allergy. Acta Paediatr 98, 1461-1467.

21. Furuhjelm C, Warstedt K, Fageras M, et al. (2011) Allergic disease in infants up to 2 years of age in relation to plasma omega-3 fatty acids and maternal fish oil supplementation in pregnancy and lactation. Pediatr Allergy Immunol 22, 505-514.

22. Duchen K, Yu G \& Bjorksten B (1998) Atopic sensitization during the first year of life in relation to long chain polyunsaturated fatty acid levels in human milk. Pediatr Res 44, 478-484.

23. Kankaanpaa P, Nurmela K, Erkkila A, et al. (2001) Polyunsaturated fatty acids in maternal diet, breast milk, and serum lipid fatty acids of infants in relation to atopy. Allergy 56, 633-638.

24. Miles EA \& Calder PC (1998) Modulation of immune function by dietary fatty acids. Proc Nutr SOC 57, 277-292.

25. James MJ, Gibson RA \& Cleland LG (2000) Dietary polyunsaturated fatty acids and inflammatory mediator production. Am J Clin Nutr 71, 343S-348S.

26. Kelley DS (2001) Modulation of human immune and inflammatory responses by dietary fatty acids. Nutrition $\mathbf{1 7}$, 669-673

27. Kim JY \& Ro JY (2005) Signal pathway of cytokines produced by reactive oxygen species generated from phorbol myristate acetate-stimulated HMC-1 cells. Scand J Immunol 62, 25-35.

28. Swindle EJ \& Metcalfe DD (2007) The role of reactive oxygen species and nitric oxide in mast cell-dependent inflammatory processes. Immunol Rev 217, 186-205.

29. Wong SW, Kwon MJ, Choi AM, et al. (2009) Fatty acids modulate Toll-like receptor 4 activation through regulation of receptor dimerization and recruitment into lipid rafts in a reactive oxygen species-dependent manner. $J$ Biol Chem 284, 27384-27392.

30. Suzuki Y, Yoshimaru T, Matsui T, et al. (2003) Fc epsilon RI signaling of mast cells activates intracellular production of hydrogen peroxide: role in the regulation of calcium signals. J Immunol 171, 6119-6127.

31. Nilsson G, Blom T, Kusche-Gullberg M, et al. (1994) Phenotypic characterization of the human mast-cell line HMC-1. Scand J Immunol 39, 489-498.

32. Bligh EG \& Dyer WJ (1959) A rapid method of total lipid extraction and purification. Can J Biochem Physiol 37, 911-917.

33. Willemsen LE, Koetsier MA, Balvers M, et al. (2008) Polyunsaturated fatty acids support epithelial barrier integrity and reduce IL-4 mediated permeability in vitro. Eur J Nutr 47, 183-191.

34. Nakano N, Nakao A, Uchida T, et al. (2005) Effects of arachidonic acid analogs on FcepsilonRI-mediated activation of mast cells. Biochim Biophys Acta 1738, 19-28.

35. Teshima R, Amano F, Nakamura R, et al. (2007) Effects of polyunsaturated fatty acids on calcium response and degranulation from RBL-2H3 cells. Int Immunopharmacol 7, 205-210

36. Calder PC, Yaqoob P, Harvey DJ, et al. (1994) Incorporation of fatty acids by concanavalin A-stimulated lymphocytes and the effect on fatty acid composition and membrane fluidity. Biochem J 300, 509-518.
37. Stubbs CD \& Smith AD (1984) The modification of mammalian membrane polyunsaturated fatty acid composition in relation to membrane fluidity and function. Biochim Biophys Acta 779, 89-137.

38. van den Elsen LW, Garssen J \& Willemsen LE (2012) Long chain $n-3$ polyunsaturated fatty acids in the prevention of allergic and cardiovascular disease. Curr Pharm Des 18, 2375-2392.

39. Gilfillan AM \& Tkaczyk C (2006) Integrated signalling pathways for mast-cell activation. Nat Rev Immunol 6, 218-230.

40. Stelekati E, Orinska Z \& Bulfone-Paus S (2007) Mast cells in allergy: innate instructors of adaptive responses. Immunobiology 212, 505-519.

41. Obata T, Nagakura T, Masaki T, et al. (1999) Eicosapentaenoic acid inhibits prostaglandin $\mathrm{D}_{2}$ generation by inhibiting cyclo-oxygenase-2 in cultured human mast cells. Clin Exp Allergy 29, 1129-1135.

42. Faveeuw C, Gosset P, Bureau F, et al. (2003) Prostaglandin $\mathrm{D}_{2}$ inhibits the production of interleukin-12 in murine dendritic cells through multiple signaling pathways. Eur J Immunol 33, 889-898.

43. Gosset P, Bureau F, Angeli V, et al. (2003) Prostaglandin $\mathrm{D}_{2}$ affects the maturation of human monocyte-derived dendritic cells: consequence on the polarization of naive Th cells. J Immunol 170, 4943-4952.

44. Barnes N, Pavord I, Chuchalin A, et al. (2012) A randomized, double-blind, placebo-controlled study of the CRTH2 antagonist OC000459 in moderate persistent asthma. Clin Exp Allergy 42, 38-48.

45. Berry M, Brightling C, Pavord I, et al. (2007) TNF-alpha in asthma. Curr Opin Pharmacol 7, 279-282.

46. Corren J (2011) Cytokine inhibition in severe asthma: current knowledge and future directions. Curr Opin Pulm Med 17, 29-33.

47. Weise C, Hilt K, Milovanovic M, et al. (2011) Inhibition of IgE production by docosahexaenoic acid is mediated by direct interference with STAT6 and NFkappaB pathway in human B cells. J Nutr Biochem 22, 269-275.

48. Dunstan JA, Mori TA, Barden A, et al. (2003) Maternal fish oil supplementation in pregnancy reduces interleukin-13 levels in cord blood of infants at high risk of atopy. Clin Exp Allergy 33, 442-448.

49. Cho KJ, Seo JM, Lee MG, et al. (2010) BLT2 is upregulated in allergen-stimulated mast cells and mediates the synthesis of Th2 cytokines. J Immunol 185, 6329-6337.

50. Fisher M, Levine PH, Weiner BH, et al. (1990) Dietary n-3 fatty acid supplementation reduces superoxide production and chemiluminescence in a monocyte-enriched preparation of leukocytes. Am J Clin Nutr 51, 804-808.

51. Fletcher MP \& Ziboh VA (1990) Effects of dietary supplementation with eicosapentaenoic acid or gamma-linolenic acid on neutrophil phospholipid fatty acid composition and activation responses. Inflammation 14, 585-597.

52. Hubbard NE, Somers SD \& Erickson KL (1991) Effect of dietary fish oil on development and selected functions of murine inflammatory macrophages. J Leukoc Biol 49, 592-598.

53. Joe B \& Lokesh BR (1994) Role of capsaicin, curcumin and dietary $n-3$ fatty acids in lowering the generation of reactive oxygen species in rat peritoneal macrophages. Biochim Biophys Acta 1224, 255-263.

54. Thompson PJ, Misso NL, Passarelli M, et al. (1991) The effect of eicosapentaenoic acid consumption on human neutrophil chemiluminescence. Lipids 26, 1223-1226.

55. Berger A, German JB, Chiang BL, et al. (1993) Influence of feeding unsaturated fats on growth and immune status of mice. J Nutr 123, 225-233. 
56. Yaqoob P \& Calder P (1995) Effects of dietary lipid manipulation upon inflammatory mediator production by murine macrophages. Cell Immunol 163, 120-128.

57. Schmutzler S, Bachmann L, Fuhrmann H, et al. (2010) PUFA-dependent alteration of oxidative parameters of a canine mastocytoma cell line. Acta Vet Hung 58, 453-464.

58. Zhang X, Dong F, Ren J, et al. (2005) High dietary fat induces NADPH oxidase-associated oxidative stress and inflammation in rat cerebral cortex. Exp Neurol 191, 318-325.

59. De Caterina R, Bernini W, Carluccio MA, et al. (1998) Structural requirements for inhibition of cytokine-induced endothelial activation by unsaturated fatty acids. J Lipid Res 39, $1062-1070$.

60. Sausenthaler S, Koletzko S, Schaaf B, et al. (2007) Maternal diet during pregnancy in relation to eczema and allergic sensitization in the offspring at $2 \mathrm{y}$ of age. Am J Clin Nutr 85, 530-537.

61. Hundley TR, Prasad AR \& Beaven MA (2001) Elevated levels of cyclooxygenase- 2 in antigen-stimulated mast cells is associated with minimal activation of p38 mitogen-activated protein kinase. J Immunol 167, 1629-1636.

62. Hirasawa N, Izumi S, Linwong W, et al. (2003) Inhibition by dexamethasone of interleukin 13 production via glucocorticoid receptor-mediated inhibition of c-Jun phosphorylation. FEBS Lett 554, 489-493.

63. Corren J, Busse W, Meltzer EO, et al. (2010) A randomized, controlled, phase 2 study of AMG 317, an IL-4Ralpha antagonist, in patients with asthma. Am J Respir Crit Care Med 181, 788-796

64. Woods RK, Thien FC \& Abramson MJ (2002) Dietary marine fatty acids (fish oil) for asthma in adults and children. The Cochrane Database of Systematic Reviews, CD001283.

65. Bath-Hextall FJ, Jenkinson C, Humphreys R, et al. (2012) Dietary supplements for established atopic eczema. The Cochrane Database of Systematic Reviews, issue 2, CD005205. 